\title{
An Energy Analysis on Gasification of Sewage Sludge by a Direct Injection in Supercritical Water
}

\author{
Riza Yukananto, Alexander C. Louwes, Eddy A. Bramer, Gerrit Brem \\ Thermal Engineering Group, Faculty of Engineering Technology, University of Twente, Enschede, The Netherlands \\ Email: r.yukananto@utwen te.nl
}

How to cite this paper: Yukananto, R., Louwes, A.C., Bramer, E.A. and Brem, G. (2017) An Energy Analysis on Gasification of Sewage Sludge by a Direct Injection in Supercritical Water. American Journal of Analytical Chemistry, 8, 753-773. https://doi.org/10.4236/ajac.2017.812055

Received: October 20, 2017

Accepted: December 2, 2017

Published: December 5, 2017

Copyright (c) 2017 by authors and Scientific Research Publishing Inc. This work is licensed under the Creative Commons Attribution International License (CC BY 4.0).

http://creativecommons.org/licenses/by/4.0/

\begin{abstract}
Supercritical Water Gasification is an efficient technology in converting wet biomass into $\mathrm{H}_{2}$ and $\mathrm{CH}_{4}$ in comparison to other conventional thermochemical processes. Coke deposition, however, remains as a major challenge in this technology. Coke formation is the result of polymerization reactions that take place at sub-critical conditions. Directly injecting the relatively unheated wet biomass feed into supercritical water increases the heating rate and reduces the residence time of the feed in the sub-critical condition. This leads to a minimized coke formation in the process. However, a non-isothermal mixing takes place during this direct injection that is less energy-efficient. In addition, the biomass feedstream experiences less pre-heating that means less heat recovery from the product gas. These two aspects might reduce the overall process performance. Parametric studies of key operating parameters, such as operating temperature, dry matter content, bypass water ratio and heat exchanger effectiveness, are carried out to investigate the influence of direct injection to the thermal efficiency of the system. Subsequently, optimization using pinch analysis is conducted to the system with direct injection. Finally, an operating window for optimum performance of the optimized direct injection gasification system is proposed.
\end{abstract}

\section{Keywords}

Supercritical Water Gasification, System Model, Sewage Sludge,

Coke Formation, Pinch Analysis

\section{Introduction}

At present, the world relies heavily on fossil fuel as its major source of energy for transportation, heating and electricity generation. It is of utmost importance for 
the world to hasten its effort in utilizing renewable energy sources. There is a considerable amount of biomass available [1], although a substantial part is not suitable for common conversion processes as it contains over $80 \mathrm{wt} \%$ of water. These highly aqueous sources are termed wet biomass and some examples are food waste, sewage sludge and manure. To overcome the high water content, supercritical water gasification (SCWG) is one of the technologies that can be used, and it is currently considered to be the most efficient technology to process wet biomass [2].

SCWG is a thermochemical conversion process that uses supercritical water (SCW) as a reaction medium. The dielectric constant of water reduces to a very low value when water reaches its supercritical condition, which leads to the ability to dissolve organic compounds [3]. The overall heat transfer during the conversion process also increases when organics dissolve in water and becomes a homogenous solution [4] [5]. As the water fraction in wet biomass is used in the conversion reactions in SCWG, it eliminates the need for drying, which is a considerable advantage in terms of energy efficiency. In addition to this, SCW experiences a significant decrease of viscosity and density that contributes to an improved mass transfer [6] [7]. It has to be noted that there is a large variation of the specific heat capacity during the transition of water to its supercritical state [8] [9]. This ultimately leads to a high heating requirement, making a good heat recovery system necessary to obtain high energy efficiencies.

Despite the advantages, this technology is not yet ready for industrial application and is still mainly used on laboratory scale [10] using a simple biomass compound. Development is still taking place and the most recent development is the use of sewage sludge in a continuous reactor [11]. In addition to this, the concept of SCWG utilization in a biorefinery is also gaining attention in recent years [12]. These recent developments, however, indicate the importance of overcoming a number of challenges [13]:

- Plugging due to coke formation;

- Plugging due to salt precipitation;

- Feed pumpability;

- Reactor corrosion.

The focus of this research is plugging due to coke formation. Coke that is formed during the gasification process tends to deposit on the inner wall of the reactor [14]. This coke deposition might cause reactor plugging which is harmful from a practical point of view [15]. Chuntanapum and Matsumura [16] experience this in their reactor when investigating the gasification of 5-hydroxymethylfurfural. Chuntanapum and Matsumura [17] then observe that coke is only formed at subcritical conditions due to the polymerization of reaction intermediates. It is also observed that there are few successful studies on gasification of wet biomass at moderate temperature $\left(400^{\circ} \mathrm{C}-450^{\circ} \mathrm{C}\right)$ [18]. Zöhrer et al. [19] then states that a fast heat-up of the wet biomass can minimize the unwanted coke formation. A fast heating rate can be achieved by injecting a partially heated wet biomass feed directly into hot supercritical water. 
The main objective of this research is to investigate and to optimize the performance of a SCWG system that employs a Direct Injection (DI) approach. A system model will be used to analyze the system performance. This research is a follow-up of previous work by Yukananto et al. [20] that investigates an ideal case flow process. The current study considers two types of processes that are based on VERENA pilot plant in Germany, the Reference Premixed (RP) system [21] and the DI system [22]. The RP system makes use of premixed biomass and water (both at room temperature) as its feedstream [23] [24]. This mixed stream is preheated using product gas before it enters the reactor. The DI system uses wet biomass and water as its feedstreams. The water stream is heated up to its supercritical condition (approximately $420^{\circ} \mathrm{C}$ and $25 \mathrm{MPa}$ ) using the product gas, and is subsequently mixed with a partially heated wet biomass stream to reduce char formation.

DI system experiences a non-isothermal mixing process which is known to reduce the energy efficiency of the system [25]. In addition to this, partial heating up of wet biomass in the DI system also increases the amount of residual heat in the product gas, which will significantly reduce the energy efficiency in comparison to the RP system. Bendig et al. [26] defines waste heat into two types: a) avoidable waste heat; b) residual heat. Residual heat is any type of heat that should be released to the ambient condition using a cold utility (cooler).These two aspects make it important to study the influence of utilizing the DI system on the overall system performance. Furthermore, the flow process of the DI system should be optimized to enhance its performance. Several key operating parameters that give insights in this investigation are:

1) Operating temperature;

2) Feed concentration (Dry Matter Content, DMC), which represents the total weight percentage of biomass in the system;

3) Bypass Water Ratio (BWR), which represents the ratio of bypass water to the total reactor feed steam;

4) Heat Exchanger (HE) effectiveness.

The following sections first present the methodology used to develop both RP and DI models using the flow sheet program UniSIM. After that, performance differences when utilizing glycerol and sewage sludge in the RP system are described. Next, the effect of utilizing the DI system and several of its key operating parameters are studied. Subsequently, optimization of the system using pinch analysis is introduced. This optimization is conducted based on the operating conditions of the DI system in the VERENA pilot plant [22]. Finally, an operating window to achieve the highest performance for the optimized DI system is proposed.

\section{Methodology}

This section describes the tools and assumptions that are used to developed the model. Indicator that is used to determine the performance of the system is de- 
fined. Afterward, both the RP system and DI system are explained thoroughly. In addition to this, limitations of the system and the analyzed feedstocks are discussed

\subsection{Tools and Assumptions}

The system model for the SCWG process is developed using UniSIM. In this model, chemical equilibrium is assumed, as there is a lack of information on kinetics and reaction mechanisms for the lumped compounds used to imitate the sewage sludge. Minimization of Gibbs free energy is used and therefore the calculation is made based on the maximum possible theoretical yield [6] [27]. It should be taken into account that this may lead to an overestimation of the system's performance. This result, however, can be used to predict thermodynamic limits as a guide for evaluation and improvement of a process design [27] [28]. Furthermore, throughout the process, constant pressure is assumed. This is deemed reasonable as it is observed that pressure variations in the SCWG process are less significant for the gas yield compared to e.g. the effect of the temperature [29]. Adiabatic conditions are also assumed throughout the process. Due to the low concentrations of other gas components, only $\mathrm{H}_{2}, \mathrm{CO}, \mathrm{CO}_{2}, \mathrm{CH}_{4}$, $\mathrm{C}_{2} \mathrm{H}_{4}$ and $\mathrm{C}_{2} \mathrm{H}_{6}$ are taken into account [30]. Finally, the separation of $\mathrm{H}_{2}$ and $\mathrm{CH}_{4}$ with the rest of the components is done at atmospheric temperature.

\subsection{Performance Indicators}

Bendig et al. [25] describes several performance indicators that are commonly used, which are: a) Energy content indicator (thermal efficiency); b) Exergy content indicator; c) Thermal pinch (pinch analysis); d) Water pinch. Exergy indicator and water pinch are not in the scope of the investigation and will not be reviewed.

Figure 1(a) and Figure 1(b) show the process flowsheets of the RP and DI system. In these flowsheets the thermal efficiency is described as energy produced by the process $\left(\mathrm{H}_{2}\right.$ and $\mathrm{CH}_{4}$ gas) minus the energy consumptions within the system, divided by the energy input [31]. The remaining burnable species (e.g. $\mathrm{CO}$ ) are not included in the calculation as their energy contents are insignificant in comparison to either $\mathrm{H}_{2}$ or $\mathrm{CH}_{4}$ (e.g. $\mathrm{CO}$ contributes to less than $2 \%$ of the total energy).The fuel required by the methane burner is one of the energy consumption within the system. The other energy consumption is the pump's duty, which is usually low as water is an incompressible substance. The energy input is the Low Heating Value (LHV) of the provided feed. Accordingly, the thermal efficiency $(\eta)$ of the system is defined as follows:

$$
\eta=\frac{\left(L H V_{\mathrm{H}_{2}} \times \dot{m}_{\text {prod }, \mathrm{H}_{2}}\right)+\left(L H V_{\mathrm{CH}_{4}} \times \dot{m}_{\text {prod }, C H_{4}}\right)-Q_{\text {pump }}-\left(L H V_{\mathrm{CH}_{4}} \times \dot{m}_{\text {burner }, C H_{4}}\right)}{\left(L H V_{\text {biomass }} \times \dot{m}_{\text {biomass }}\right)}(1)
$$

With m representing mass flow rate $(\mathrm{m} / \mathrm{kg})$. The amount of produced gases that is used in Equation (1) is obtained from the "cold product" stream in accordance to Figure 1(a). The fuel requirement for the burner is largely 


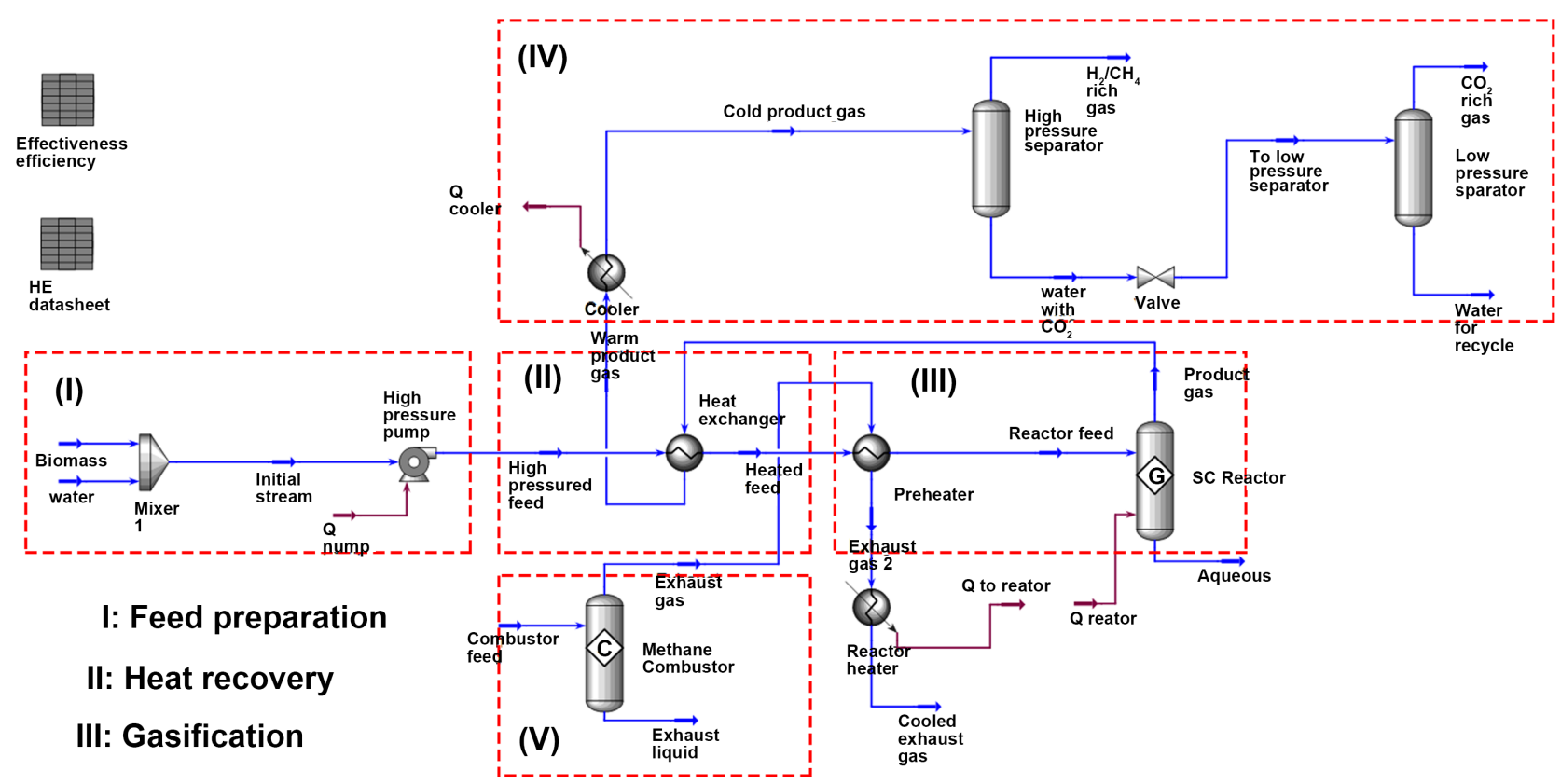

(a)

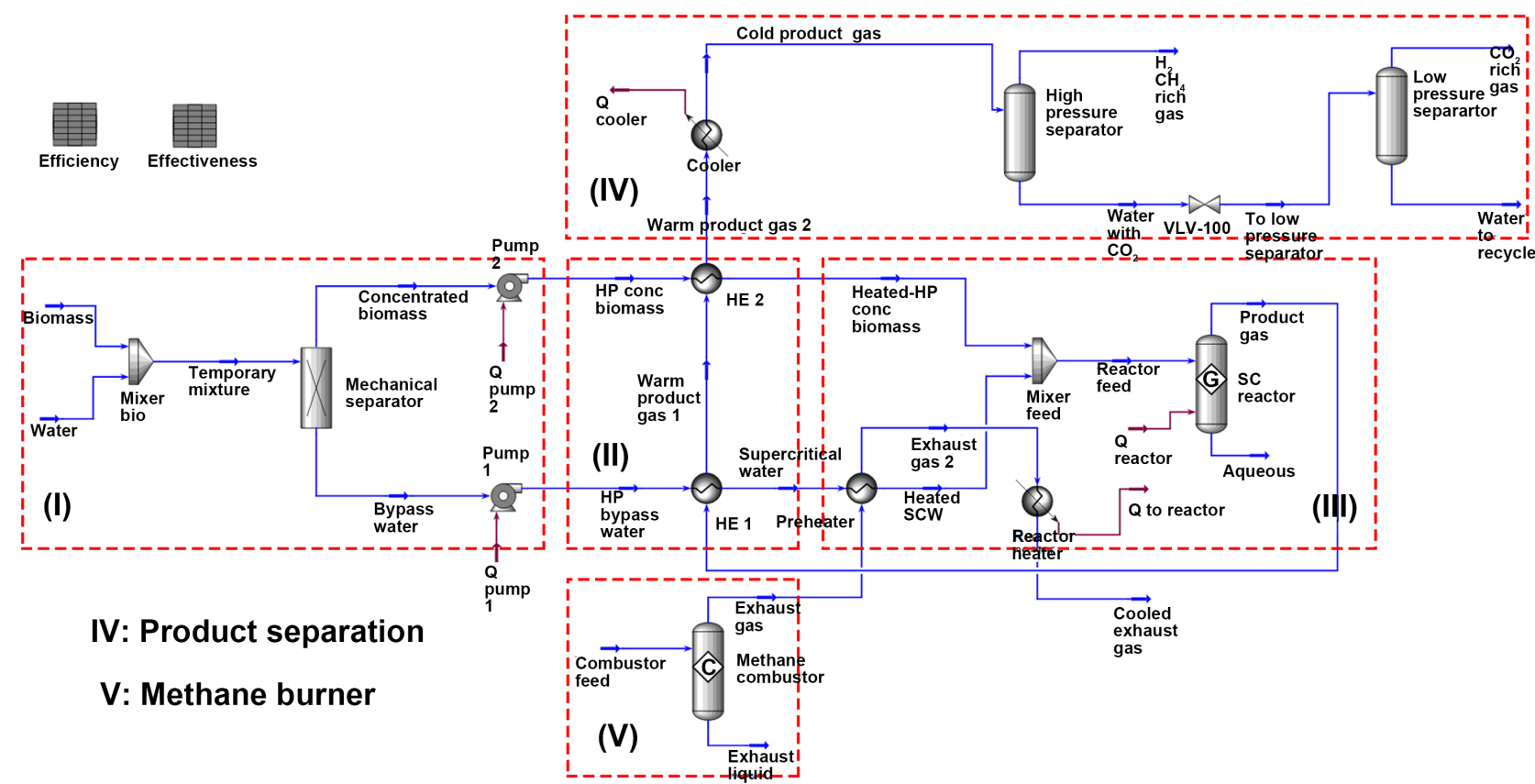

(b)

Figure 1. (a) Reference Premixed [RP] system flowsheet; (b) Direct Injection [DI] system flowsheet.

influenced by the heat recovery within the system. Therefore, HE effectiveness for recovering heat plays an important role in determining the thermal efficiency of the system. The HE effectiveness is defined as the ratio of the actual heat transferred by the HE and the maximum heat that could possibly be transferred from one stream to the other [23]. During the SCWG process, the specific heat capacity of water can change dramatically. Therefore, it is preferable to calculate 
the effectiveness of the HE using the enthalpy method, as follows:

$$
\varepsilon=q / q_{\max }=\frac{(\dot{m} \times h)_{\text {cold }, \text { out }}-(\dot{m} \times h)_{\text {cold, in }}}{(\dot{m} \times h)_{\text {hot, in }}-(\dot{m} \times h)_{\text {cold ,in }}}
$$

With $q$ representing heat flow $(\mathrm{kW})$ and $h$ representing specific enthalpy $(\mathrm{kJ} / \mathrm{kg})$. Pinch analysis is a technique to improve the performance of a system by increasing the process to process heat exchanges. There are three important points that should be followed when optimizing the system: a) heat transfer across the pinch point should not take place; b) no hot utility should be used below the pinch point; $c$ ) no cold utility should be used above the pinch point. Related to this, Bendig et al. mentions several methods that are generally used to enhance the energy usage in a process system. These methods are: internal heat recovery; water reutilization; elimination of non-isothermal mixing; condensate recovery; energy conversion and energy upgrading using a heat pump. Methodologies such as grand composite curve or the shifted combine composite curves can be used to visualize the target of the optimization [26].

\subsection{Choice of Property Method}

SCWG usually takes place at a temperature of $400^{\circ} \mathrm{C}-650^{\circ} \mathrm{C}$ and a pressure above 22.4 MPa. At such a high pressure, ideal gas assumptions can no longer be used to describe its thermodynamic and transport properties as the real gas behavior deviates significantly. In addition to this, chemical equilibrium assumptions are highly dependent of the fugacity (effective partial pressure) value of the mixture. Therefore, it is important to select the best method to approximate the values of these properties accurately.

The Equation of State (EoS) is a common method to approximate the above mentioned properties. Valderrama mentions that SRK, PR and Patel-TejaValderrama cubic EoS provide a good approximation for high pressure processes between polar and non-polar mixtures [32]. Subsequently, mixing rules have to be used in order to relate the EoS parameters of each component in the mixture. Valderrama also states that mixing rules such as Van der Waals, Wong-Sadler or Panagiotopoulos-Reid, can be used, but those that are proposed by Soave and Twu give better results for calculations in the supercritical region [32]. In this research, the Soave-Redlich-Kwong with the Twu mixing rule (SRK-Twu) is selected. This method is already tested and the results are similar in comparison to other work related to SCWG process modeling [23].

\subsection{Process Flow Modelling}

\subsubsection{Process Flowsheet}

Two different flow processes are described in this subsection. The RP configuration can be categorized into 5 different stages, shown in Figure 1(a). In the first stage the DMC of the overall feedstream is regulated by mixing a specified amount of water with biomass. Then the "initial stream" is brought to its operating pressure. Subsequently, the "high pressure feed" is sent to the HE so that it 
can recover some heat from the hot "product" gases to reduce the residual heat. The "heated feed" has already reached supercritical state when it exits the HE.

Afterwards, the "heated feed" is preheated even further and is then supplied to the reactor where the gasification reaction occurs. Both the heat required for the preheating and for the reactor originate from the hot "exhaust gas" from a methane burner. The Gibbs reactor employs an infinite residence time for the incoming feed stream. The energy in the hot "product gas" is recovered in the HE to preheat the "high pressure feed". Separation of $\mathrm{CH}_{4}$ and $\mathrm{H}_{2}$ from the water- $\mathrm{CO}_{2}$ mixture can easier be performed at ambient temperature, therefore a cold utility is used to cool down the "cold product". The water- $\mathrm{CO}_{2}$ mixture is then expanded to ambient pressure and is further separated into $\mathrm{CO}_{2}$-rich gas and tail water. Tail water might be recycled back into the system or might need further mineral processing.

The DI configuration is designed so that the biomass compound can be injected directly into hot supercritical water to experience a fast heat-up that leads to a reduction of coke formation. Figure 1 (b) presents the flowsheet of this DI system. The DI system differs from the RP system because of the existence of a mechanical separator at the start of the process, and different locations of HEs to recover heat from the hot "product gas". The overall DMC in the system is regulated by mixing the biomass compound with water. The "temporary mixture" enters the mechanical separator that separates the mixture into: i) "concentrated biomass" that consists of hot biomass compound and water; ii) "bypass water" which is purely water. This step is performed to accommodate an easier comparison between feed flow rate and concentration in reference to the RP system. Both of these streams are then pressurized to the operating pressure.

Subsequently, the "HP bypass water" is then heated to its supercritical state by sending it to a HE to recover some heat from the hot "product gases". In addition to that, this "supercritical water" stream is heated up further using the hot exhaust gas from the methane burner. The "HP concentrated biomass" is also preheated to just below the critical point by using the "warm product gas 1". These two streams are mixed together and are then referred to as "reactor feed". This mixing is carried out to achieve a fast heat-up of preheated injected-biomass ("heated HP concentrated biomass"). In doing so, injected biomass will have a shorter residence time in the near-critical region, which is presumed to reduce coke formation. This "reactor feed" that enters the reactor is heated up to its operating temperature and the gasification process will then occur. The hot "product gas" leaves the reactor into the two HEs. The "product gas" is then cooled down and is separated in the same way as done in the RP system.

\subsubsection{Direct Injection System Limitation}

The RP system is modified into the DI system to minimize coke formation that might lead to plugging. In his investigation, Knezevic et al. observes that both decomposition and coke formation already occur at $250^{\circ} \mathrm{C}$. The rate of these 
reactions, however, is still low at this temperature as this is implied by the low conversion rate of glucose itself [14]. Chuntanapum and Matsumura show that the kinetics of char formation increases intensively at $300^{\circ} \mathrm{C}-370^{\circ} \mathrm{C}$, and reduce dramatically at temperatures higher than $400^{\circ} \mathrm{C}$ [17]. It is also found that char formation kinetics at $300^{\circ} \mathrm{C}$ is comparable to the kinetics of gas formation. Taking this into consideration, the "heated HP concentrated biomass" temperature in this model is chosen to not exceed $300^{\circ} \mathrm{C}$ and be limited to $280^{\circ} \mathrm{C}$ as a safety measure.

Zöhrer et al. also states that a fast heat-up of the wet biomass can minimize the unwanted coke formation [19]. Chuntanapum and Matsumura observe that the coke formation rate is reduced dramatically above the critical point [17]. Therefore, the temperature of the resulting mixture from the "heated HP concentrated biomass" and the "heated SCW", which is referred to as "reactor feed", should exceed $375^{\circ} \mathrm{C}$. Finally, it is assumed that the pinch temperature in the HEs is $15^{\circ} \mathrm{C}$. The pinch temperature is the minimum temperature difference in a $\mathrm{HE}$, and the location at which this takes place is referred to as the pinch point.

Related to the pumping capability of wet biomass (slurry), Yakaboylu et al. states that in a laboratory environment, it is possible to pump wet biomass of up to $40 \mathrm{wt} \%$ dry matter content [13]. Stolten et al. states that depending on the type of wet biomass, only biomass that has up to $20 \mathrm{wt} \%$ dry matter content is pumpable [33]. This statement is also supported with a demonstration by the pilot plant in Verena [22]. The pinch based optimization should take these information into consideration.

\subsubsection{Analyzed Feedstock}

In the present research firstly a simple model compound in the RP configuration will be used to represent the wet organic compound. Afterwards, a real wet organic compound is simulated using the lumped component approach. The molecular formula that is chosen for sewage sludge is $\mathrm{CH}_{1.498} \mathrm{O}_{0.413}$ with an $\mathrm{HHV}$ of $22.4 \mathrm{MJ} / \mathrm{kg}$ [34] [34]. The amount of C-H-O molecules is the most important factor to be considered when implementing the Gibbs reactor. The molecular formula of sewage sludge is obtained by mixing acetic acid, diketene, propanone and benzene with various proportions. The surrogate weight percentages of each compound are 30,45,15 and 10, respectively. These compounds are used since they are possible compounds found in real sewage sludge. Differences of the other thermodynamic properties due to utilizing these compounds are assumed to be negligible.

\section{System Performance: Parametric Investigations}

This section presents the performance differences when utilizing two different biomass feed. Next, the influence of directly injecting the relatively cold biomass into supercritical water to the system's performance is investigated. Subsequently, the influence of key operating parameters to the performance of the DI sys- 
tem is looked into. Finally, an optimum operating window for the DI system is proposed.

\subsection{Thermal Efficiency of Real and Model Compounds}

Two different compounds (glycerol and sewage sludge) are used with RP operating at $575^{\circ} \mathrm{C}$ and $25 \mathrm{MPa}$. A comparison of thermal efficiency of these two compounds with varying DMC is presented in Figure 2(a). Increasing the DMC leads to an increase in thermal efficiency for both glycerol and sewage sludge. It can also be seen that usage of glycerol leads to a system with a lower efficiency. Approximately $19 \%$ difference of thermal efficiency can be seen at $8 \mathrm{wt} \% \mathrm{DMC}$, and approximately $5 \%$ difference at $20 \mathrm{wt} \% \mathrm{DMC}$.

The difference in thermal efficiency occurs to the fact that glycerol produces a significantly lower amount of $\mathrm{CH}_{4}$ and slightly less $\mathrm{H}_{2}$ in comparison to sewage sludge. Glycerol, having a $4.54 \mathrm{C}: \mathrm{H}$ ratio, is theoretically expected to produce more $\mathrm{CH}_{4}$ and $\mathrm{H}_{2}$ in comparison to sewage sludge that has a $\mathrm{C}: \mathrm{H}$ ratio of 7.9. However, Louw stated that oxygen content significantly affects the yield when a feedstock's C:H ratio is lower than 10 [35]. Accordingly, glycerol, which has an oxygen content higher than $50 \mathrm{wt} \%$, produces less yield in comparison to sewage sludge, which has an oxygen content of approximately $30 \mathrm{wt} \%$. A prediction of the maximum yield can be used as a guideline to improve the process design. Therefore, all of the subsequent cases are investigated using sewage sludge as a feedstock.

\subsection{Effect of Direct Injection}

Non-isothermal mixing and partial heating of "concentrated biomass" stream are expected to reduce the thermal efficiency of the system. The thermal efficiency comparison of the RP and DI systems, at $575^{\circ} \mathrm{C}, 25 \mathrm{MPa}$ and $0.4 \mathrm{BWR}$, is visualized in Figure 2(b). BWR represents the ratio of "bypass water" to the “reactor feed" in Figure 1(b). Both systems operate with a maximum HE effectiveness, which represents the highest realizable effectiveness while maintaining $15^{\circ} \mathrm{C}$ difference in the HE. This value can be different in every system, depending on the mass flow rate in the HE.

Figure 2(b) shows that at $8 \mathrm{wt} \%$ DMC, the thermal efficiency of the DI system reduces by approximately $23 \%$ points compared to the RP system. When it is operated at $20 \mathrm{wt} \% \mathrm{DMC}$, the difference in thermal efficiency is approximately $10 \%$ points. These are directly related to the fact that the DI system operates with several limitations mentioned in subsection 2.4.2. (e.g. the maximum biomass preheating temperature of $280^{\circ} \mathrm{C}$ ). These limitations cause the non-optimal heat transfer configuration in the system, which leads to a reduction of the thermal efficiency. Aside from that, the non-isothermal mixing process that is introduced in the DI system also reduces the thermal efficiency of the system.

The reduction of thermal efficiency is less significant when a higher DMC is used. With an equal BWR, a higher DMC leads to lower amounts of water in the 


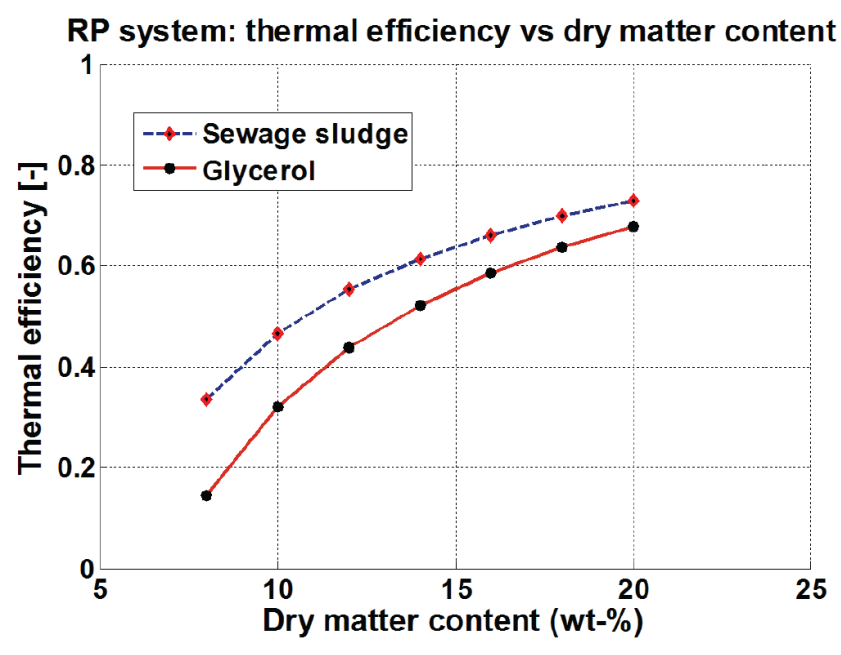

(a)

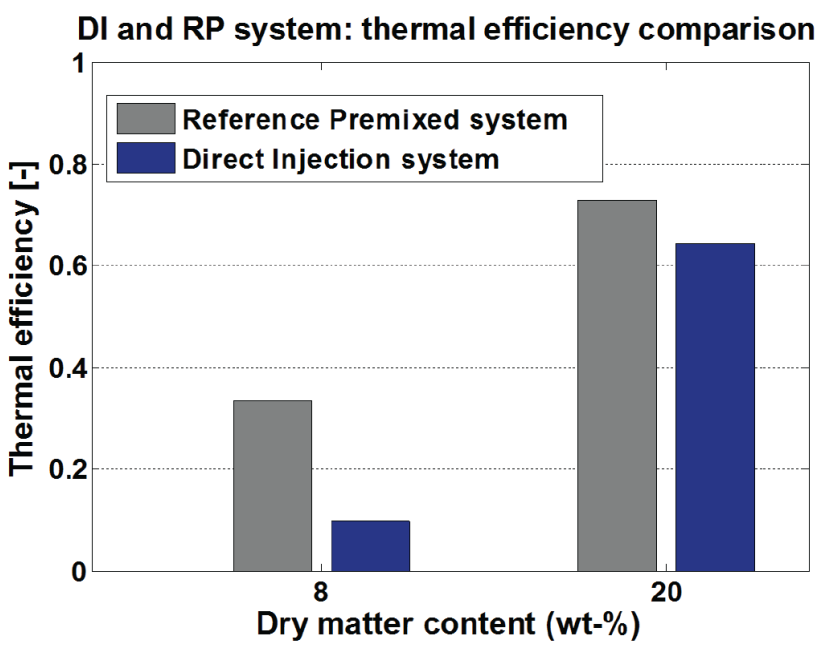

(b)

Figure 2. Thermal efficiency comparison at $575^{\circ} \mathrm{C}, 25 \mathrm{MPa}$. (a) RP system using glycerol and sewage sludge, (b) RP and DI system using sewage sludge.

"heated HP concentrated biomass". This reduces the energy required by the reactor and hence the fuel consumption for the methane burner. The following subsection will investigate in more detail the key operating parameters that cause this reduction of thermal efficiency.

\subsection{Effect of Key Operating Parameters in the DI System}

Several key operating parameters have been investigated: temperature, DMC, BWR and HE effectiveness. The requirements that are mentioned in Subsection 2.4.2 have to be satisfied for every variation of these key parameters. The proposed optimum operating window for the DI system is made based on these results.

The first key parameter is the reactor operating temperature. The investigation is done at $12 \mathrm{wt} \% \mathrm{DMC}, 25 \mathrm{MPa}$, and a BRW of 0.4. The influence of operating temperature on the thermal efficiency at constant HE effectiveness is illustrated in Figure 3(a). Figure 3(a) also indicates the influence of the operating temperature on the "reactor feed", which has to be above $375^{\circ} \mathrm{C}$.

It can be seen that the thermal efficiency of the system reduces as the operating temperature increases. This reduction of efficiency is caused by the increase of residual heat in the "warm product gas" and "cooled exhaust gas". Figure 3(b) demonstrates the effect of operating temperature on the amount of residual heat and the gas yield in the product gas stream. Even though the $\mathrm{H}_{2}$ yield increases with operating temperature, its energy contribution is less than the energy loss by residual heat and reduction of $\mathrm{CH}_{4}$ produced in the product gas.

Figure 3(a) also shows that operating with reactor temperatures below $650^{\circ} \mathrm{C}$ will lead to a reactor feed temperature of less than $375^{\circ} \mathrm{C}$. Figure $3(\mathrm{c})$ shows the reactor feed temperature at maximum HE effectiveness. Figure $3(\mathrm{c})$ illustrates that the requirement mentioned in subsection 2.4.2 is satisfied when operating at 


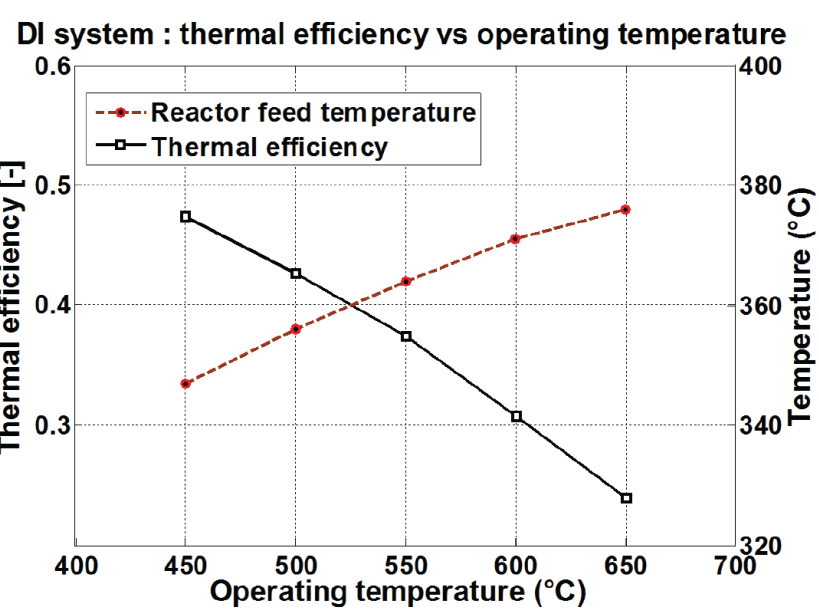

(a)

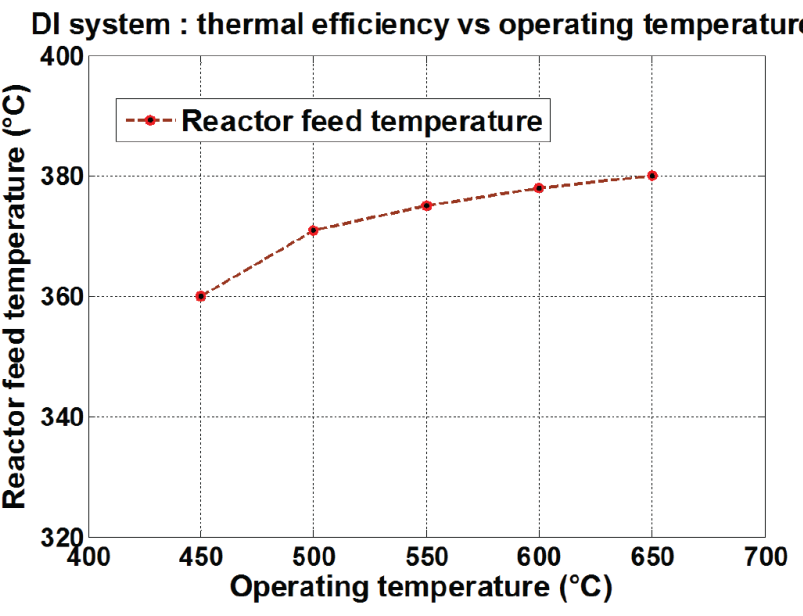

(c)

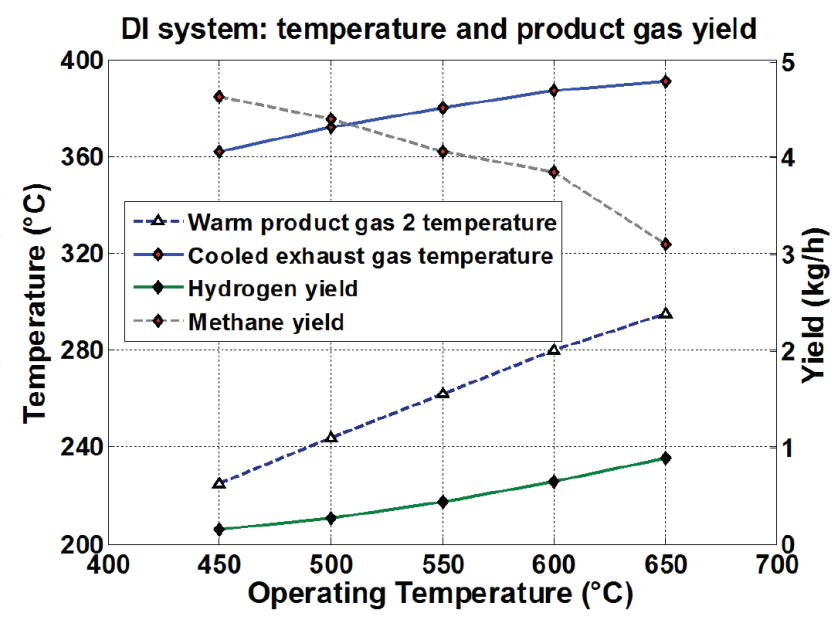

(b)

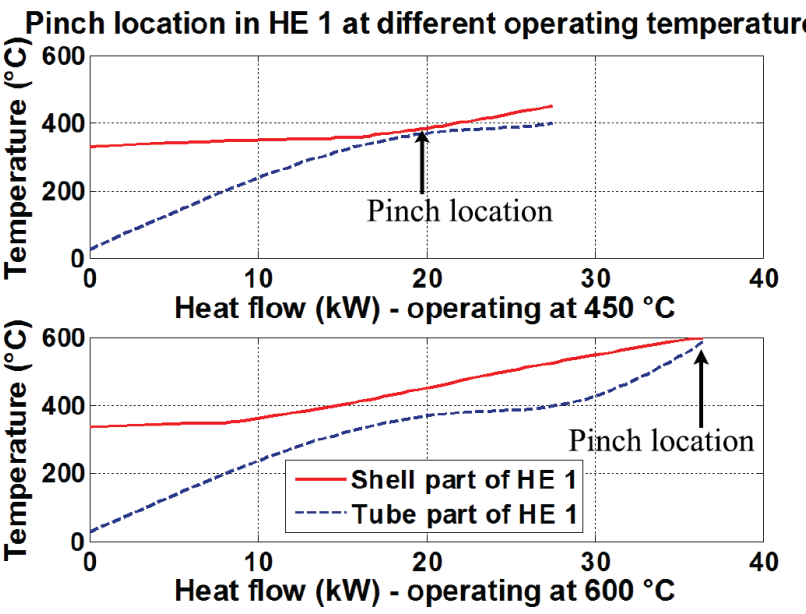

(d)

Figure 3. (a-c) Influence of operating temperature for DI system using sewage sludge at $12 \mathrm{wt} \% \mathrm{DMC}, 25 \mathrm{MPa}$ and $0.4 \mathrm{BWR}$. (a) Influence on thermal efficiency and reactor feed temperature at constant HE effectiveness; (b) Influence on waste gas temperature and $\mathrm{H}_{2}$ yield at constant $\mathrm{HE}$ effectiveness; (c) Reactor feed temperature at maximum HE effectiveness; (d) Pinch point locations inside "HE 1" at various operating temperatures.

a temperature higher than $575^{\circ} \mathrm{C}$. The sharp increase at the beginning of Figure 3 (c) occurs due to the limited amount of thermal energy in the product gas at a temperature of $450^{\circ} \mathrm{C}$ to transform "HP bypass water" into its supercritical state. This changes the pinch point location to the center of " $H E 1$ ", and thus the outlet temperature of the SCW is far below the inlet temperature of the hot product gas. This results in a lower reactor feed temperature after mixing of the SCW stream and the injected-feed stream. In contrast to what is taking place at 450 ${ }^{\circ} \mathrm{C}$, the pinch point location at higher operating temperature (e.g. at $600^{\circ} \mathrm{C}$ ) is located near the outlet of " $H E 1$ ". These pinch point locations inside " $H E 1$ " with different operating temperatures are shown in Figure 3(d).

The second key parameter is the DMC. Figure 4(a) presents the thermal efficiency of the DI system for various DMCs. The DI system is operating at $575^{\circ} \mathrm{C}$ and $25 \mathrm{MPa}$ at constant HE effectiveness, and has a BWR of 0.4. It can be seen 


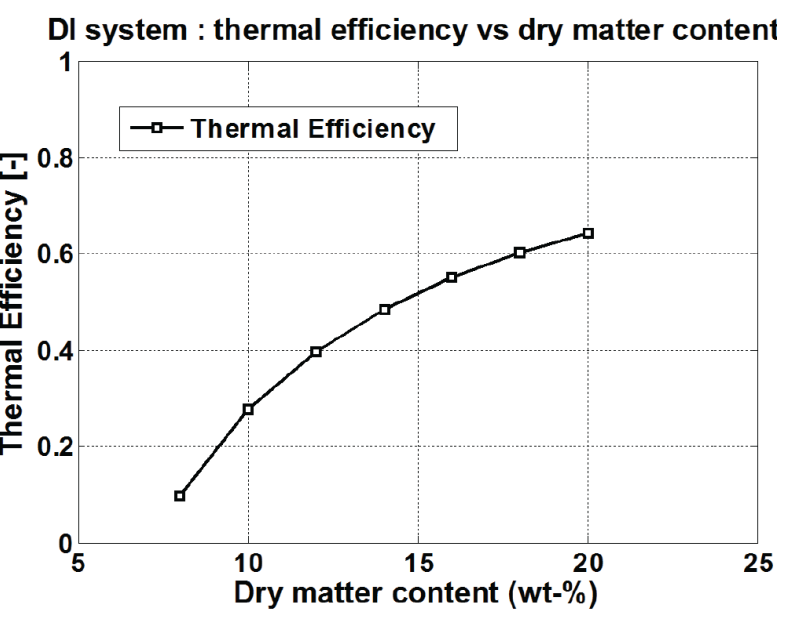

(a)

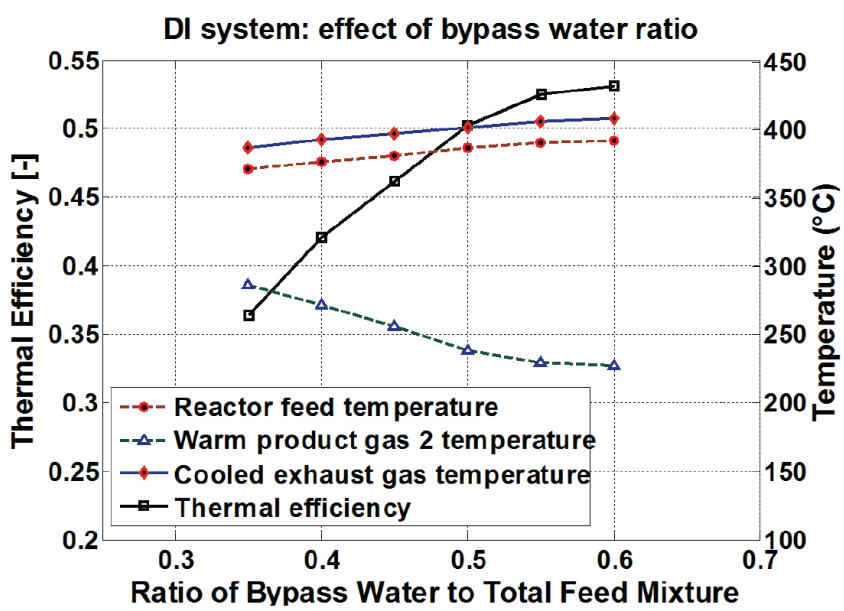

(c)

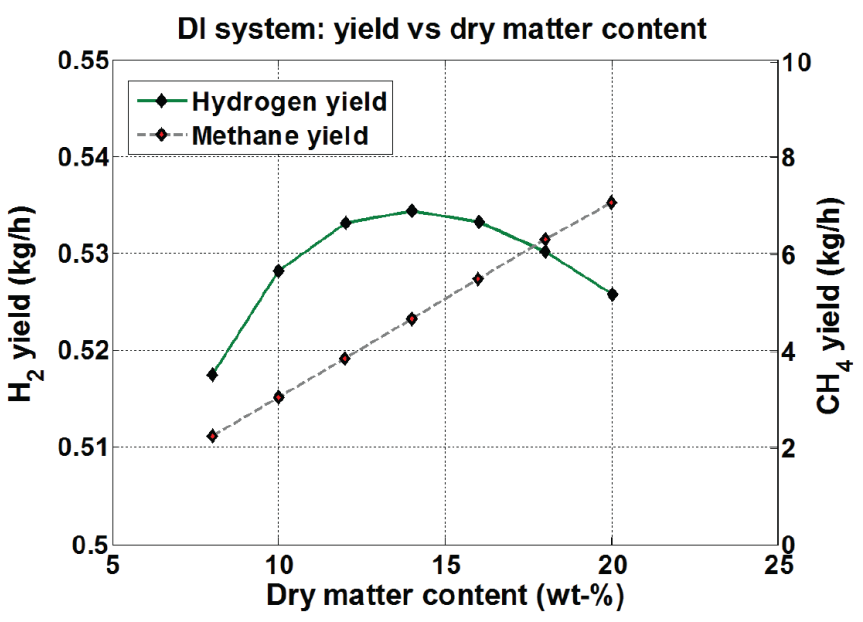

(b)

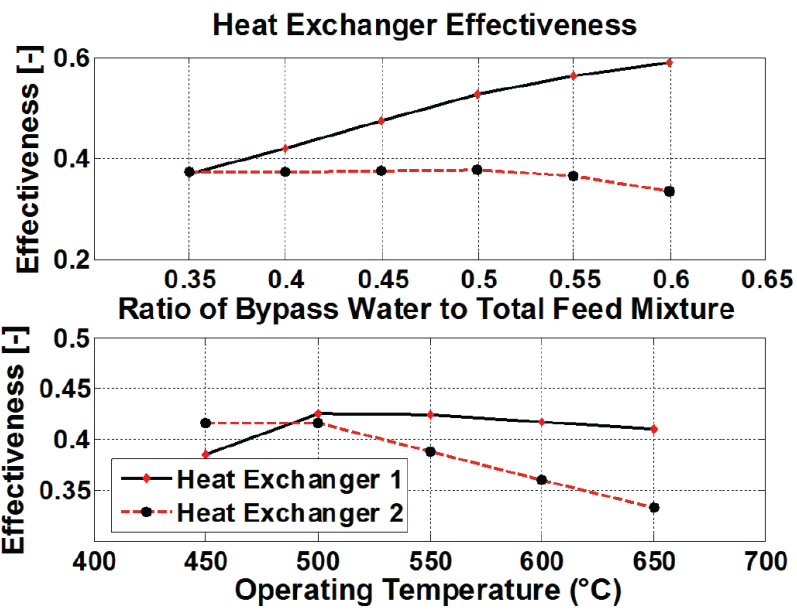

(d)

Figure 4. (a-b) Influence of DMC on DI system using sewage sludge at $575^{\circ} \mathrm{C}, 25 \mathrm{MPa}$ and $0.4 \mathrm{BWR}$. (a) Influence on thermal efficiency; (b) Influence on $\mathrm{H}_{2}$ and $\mathrm{CH}_{4}$ yield; (c) Influence of BWR on DI system using sewage sludge at $12 \mathrm{wt} \%, 575^{\circ} \mathrm{C}$ and 25 $\mathrm{MPa}$; (d) Influence of BWR $\left[575^{\circ} \mathrm{C}\right]$ and operating temperature [0.4 BWR] on HEs effectiveness using sewage sludge at $12 \mathrm{wt} \%$ and $25 \mathrm{MPa}$.

that the increase of thermal efficiency (inclination) is higher at a DMC below 14 $\mathrm{wt} \%$ in comparison to the gradient at a DMC above $14 \mathrm{wt} \%$. The curve going flatter with the increase of DMC means that the increase of this parameter is less significant at higher value.

At a DMC-range of $8-14 \mathrm{wt} \%$, any increase in feed concentration will increase both the methane and hydrogen yield in the product gas stream. When the system operates at a DMC of $14-20 \mathrm{wt} \%$, any increase in feed concentration will increase the methane yield and decrease the hydrogen yield. This can be seen in Figure 4(b). The changes in the (cooled) product gas temperature are not significant enough to affect the overall thermal efficiency.

The third key parameter is the BWR. The investigation is conducted at $575^{\circ} \mathrm{C}$, $25 \mathrm{MPa}$ and $12 \mathrm{wt} \% \mathrm{DMC}$. Influence of the BWR on the thermal efficiency, reactor feed temperature and waste gas temperature is displayed in Figure 4(c). 
It can be seen that the increase of this ratio results in a significant increase of the thermal efficiency. An increase of this ratio physically means that the system delivers a higher bypass water flow rate in comparison to the injected feed flow rate. This makes it possible for " $H E 1$ " to recover more heat from the hot product gases, and in turn leads to a decrease of the residual heat in the cooled product gas and less fuel consumption in the burner.

A higher flow rate of hot bypass water ("heated $S C W$ ") means that the stream contains more sensible energy. Mixing of this stream with the "heated HP concentrated biomass" will increases the sensible energy in the reactor feed. This leads to a decrease of the required energy by the reactor to reach the designed operating temperature. These two reasons lead to the steep increase of thermal efficiency.

The slope of the graph, however, changes after it reaches a BWR of 0.5. As the BWR is further increased, the "HP bypass water" stream requires more heat to achieve its supercritical state. This leads to the relocation of pinch point to the center of the " $H E 1$ ", similar to what is described in Figure 3(d). This reduces the temperature of the "heated $S C W$ " and also the "heated HP concentrated biomass" stream, which leads to a less significant increase in thermal efficiency, as demonstrated in the graph. It also has to be considered that increasing the BWR means that the amount of DMC in the pumped slurry is increased. Taking into account that pumpability of the wet biomass is a challenge by itself, it is advisable not to use a high BWR.

The fourth key parameter is the effectiveness of " $H E 1$ " and " $H E 2$ ". It has been mentioned above that the "reactor feed" temperature and the "warm product gas 2" temperature have a significant effect on the thermal efficiency of the system. Subsequently, these two variables are changing dramatically with the variation of operating temperature and BWR. Figure 4(d) visualizes the maximum effectiveness of " $H E 1$ " and " $H E 2$ ", as a function of these two variables. This system is operated at: a) $575^{\circ} \mathrm{C}, 25 \mathrm{MPa}$ and with $12 \mathrm{wt} \% \mathrm{DMC}$; b) 0.4 BWR, $25 \mathrm{MPa}$, and with $12 \mathrm{wt} \% \mathrm{DMC}$.

Effectiveness of both HEs are below $60 \%$ at any BWR value. The effectiveness of " $H E 1$ " increases along with the increase of the BWR, whereas the effectiveness of " $H E 2$ " remains almost constant until a BWR of 0.5 and then it decreases. The effectiveness of " $H E I$ " increases significantly because it is able to recover more sensible energy due to its higher flow rate. As the BWR increases, the outlet temperature of hot gas at " $H E 1$ " decreases even further. At a BWR of 0.5, this temperature approaches the designed preheated-injected feed temperature $\left(280^{\circ} \mathrm{C}\right)$. To maintain the $15^{\circ} \mathrm{C}$ pinch, " $H E 2^{2}$ " is not able to recover any more heat, which in effect reduces its effectiveness.

At operating temperature higher than $450^{\circ} \mathrm{C}$, the $\mathrm{HE}$ effectiveness reduces along with the increase of operating temperature. The decrease of effectiveness of "HE 2" is due to the fact that the "warm product gas 1" still contains a significant amount of heat, while the "HP concentrated biomass" is only allowed to be heated up to $280^{\circ} \mathrm{C}$. The low value of the HE effectiveness means that the loca- 
tion of heat transfer is not optimal for the DI system. This phenomenon reduces the thermal efficiency of the system dramatically. Therefore, it is suggested to target the optimal heat transfer using the Heat Exchanger Network (HEN) configuration approach. HEN is a visual representation of the overall heat transfer of both hot and cold streams in a system, and can be used for energy integration analysis.

\subsection{Proposed Operating Window}

Based on the analysis shown above, an operating window that takes into account the process limitations is proposed. Figure 3 (c) shows that the minimum operating temperature to satisfy the supercritical reactor-feed after non-isothermal mixing is $570^{\circ} \mathrm{C}$. It is also shown that any further increase of the operating temperature will only result in a lower thermal efficiency. Figure 4 (d) shows that the slope of the " $H E 1$ " effectiveness reduction is getting steeper at operating temperatures above $600^{\circ} \mathrm{C}$. It also shows that the gradient of the " $H E 2$ " effectiveness is constant at temperatures above $500^{\circ} \mathrm{C}$. Therefore, the system is suggested to operate between reactor temperatures of $570^{\circ} \mathrm{C}-600^{\circ} \mathrm{C}$.

Figure 4(a) shows that it is best to operate with DMC below $14 \mathrm{wt} \%$. Increasing the DMC will further increase the thermal efficiency, however, this alters the trend of the inclination of the upward curve. It has to be noted that this value is also limited by external factors such as pumpability. Figure 4 (c) shows that the rate of increase of the thermal efficiency of the system is the highest at a BWR of $0.4-0.5$. A less significant increase of thermal efficiency can be obtained when increasing the BWR further.

\section{System Optimization: Pinch Based Design}

This section put forward the optimization of the DI system based on the pinch analysis. It starts with the determining the operating conditions that is used for the case study. Then the optimization is conducted using the HEN design method. Finally the performance of the optimized DI system is compared to the DI and RP system, and an operating window for this optimized system is proposed.

\subsection{Targeting by Pinch Analysis}

The main objective of this analysis is to optimize the system by increasing the process to process heat transfer capacity to reduce the residual heat. As was stated in 3.4., it is suggested to operate the system with operating temperature of $570^{\circ} \mathrm{C}-600^{\circ} \mathrm{C}$, and with a BWR of $0.4-0.5$. Pinch analysis is then conducted to a system that operates at $575^{\circ} \mathrm{C}$ with $0.4 \mathrm{BWR}$. A large increase of the thermal efficiency is obtained when increasing the BWR up to 0.6 and therefore this condition is also analyzed for optimization. The DMC for both analyses is set to be $12 \mathrm{wt} \%$. A total flow rate of $100 \mathrm{~kg} / \mathrm{hour}$, which corresponds to the VERENA pilot plant configuration [22], is used.

Figure 5(a) presents the combined composite curves when the DI system operates with a BRW of 0.4. A combined composite curves is a tool that visualizes 


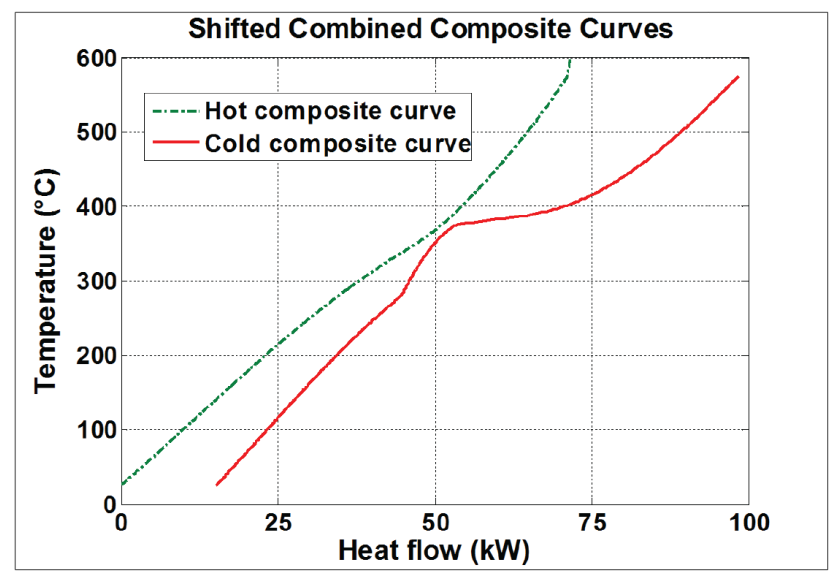

(a)

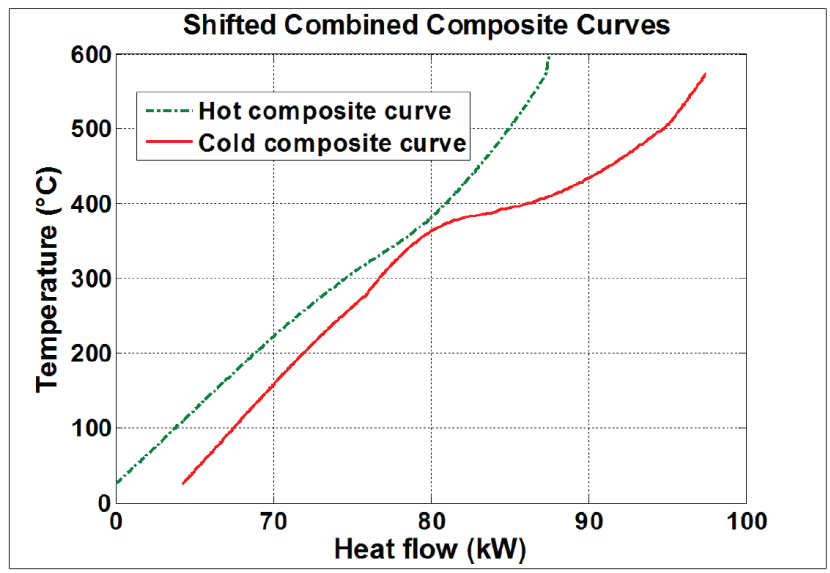

(c)

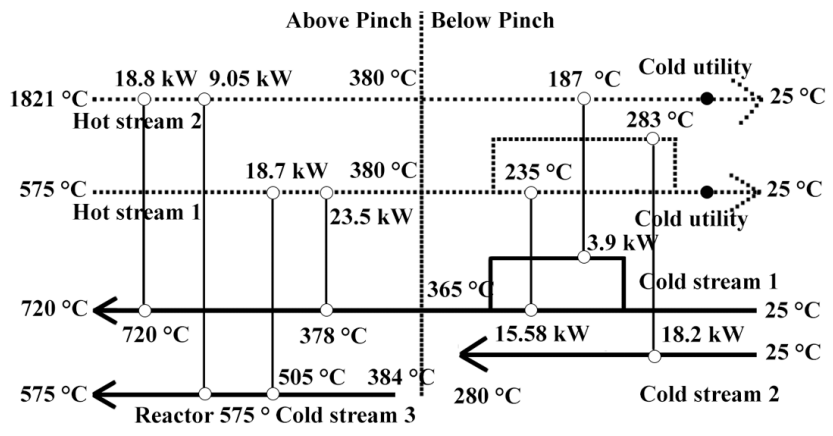

(b)

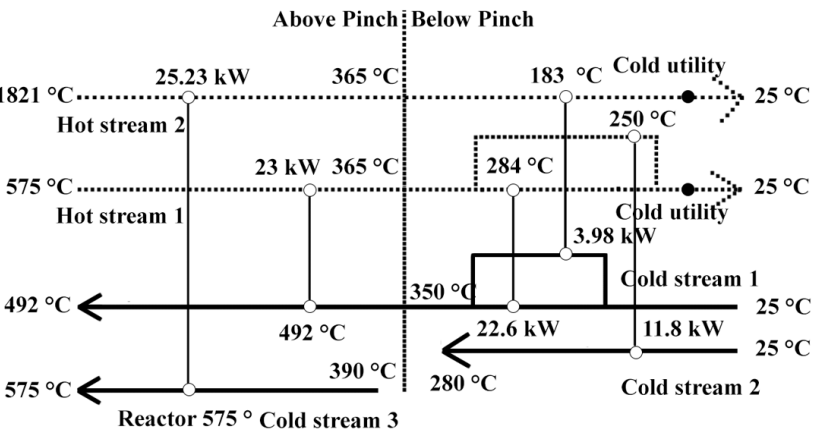

(d)

Figure 5. (a \& c) Shifted combined composite curves of DI system using sewage sludge at $12 \mathrm{wt} \% \mathrm{DMC}, 575^{\circ} \mathrm{C}$ and 25 . (a) With 0.4 BWR; (c) With 0.6 BWR; (b \& d) Heat exchanger network design for system using sewage sludge at $12 \mathrm{wt} \% \mathrm{DMC}, 575^{\circ} \mathrm{C}$ and 25; (b) With 0.4 BWR; (d) With 0.6 BWR.

heat availability and demand for both hot and cold stream in a system. In a combined composite curves graph, the area in between the curves represents the possible amount of heat that can be recovered. The cold pinch of the system is found to be located at the temperature of $365^{\circ} \mathrm{C}$. A steep increase in the cold composite curve can be seen in the range of $280^{\circ} \mathrm{C}-365^{\circ} \mathrm{C}$, after which the slope comes closer to the original trend goes quite flat. This steep increase shows that the injected feed is only preheated up to a temperature of $280^{\circ} \mathrm{C}$. The trend above $360^{\circ} \mathrm{C}$ exhibits the high variation of specific heat of water when it transforms into its supercritical state. The slope of the graph goes flat at a temperature above $376^{\circ} \mathrm{C}$. This shows that there is an increase of heat flow demand to heat up the cold flow, which emerge from the reactor feed stream after mixing.

Pinch optimization is done by considering guidelines and methods mentioned in subchapter 2.2. Figure 5(b) displays the HEN design of the optimized system. The dashed line in the figure represents the hot stream and the solid lines represent the cold stream. The hot stream above its pinch transfers $23.5 \mathrm{~kW}$ of 
its heat to let cold stream 1 (pure water stream) reach a temperature of $378^{\circ} \mathrm{C}$ and thus become supercritical. The remaining $18.7 \mathrm{~kW}$ of heat is used to heat up cold stream 3 (reactor feed stream). The hot stream 2 (burner's exhaust gas) provides $9.05 \mathrm{~kW}$ of heat to supply the reactor's heat duty. Aside from that, $18.88 \mathrm{~kW}$ of its heat is also used to superheat the cold stream 1 until it reaches the temperature of $720^{\circ} \mathrm{C}$. The reactor feed stream is obtained by mixing the pure water stream and cold stream 2 (cold injected feed). The hot stream below the pinch transfers a total of $33.7 \mathrm{~kW}$ of heat to preheat both the cold pure water stream and the cold injected feed. The hot stream is split to match the heat flow requirement from the cold streams. In addition to this, $3.9 \mathrm{~kW}$ of the heat required by the cold stream below the pinch is extracted from the hot stream 2. In this way, no hot utility is necessary to heat up the cold stream. Cold utility is used to release the heat from the hot stream until its ambient condition. The hot stream is then sent to the separator.

A different configuration for the system that operates at $575^{\circ} \mathrm{C}$ with a $\mathrm{BWR}$ of 0.6 is found. Figure 5(c) presents the combined composite curves for the DI system with these operating conditions. The cold pinch of the system is found to be located at a temperature of $350^{\circ} \mathrm{C}$. Figure 5 (c) demonstrates a less steep increase in the cold composite curve in the range of $280^{\circ} \mathrm{C}-365^{\circ} \mathrm{C}$, in comparison to Figure 5(a). This is due to a larger amount of heat flow requirement to heat up the pure water stream, which has higher flow rate. In the range of $376^{\circ} \mathrm{C}$ $392^{\circ} \mathrm{C}$, a sharper increase in the cold composite can be seen in Figure 5(c) comparison to Figure 5(a). Less heat flow requirement in that range occurs because the reactor feed after mixing has a temperature of $392^{\circ} \mathrm{C}$. This behavior relocates the cold pinch location in comparison to the previous operating conditions.

The optimized HEN design for this operating condition at a BWR of 0.6 is visualized in Figure 5(d). It can be seen that the hot stream above its pinch releases all of its energy to form the supercritical water up to a temperature of $492^{\circ} \mathrm{C}$. The reactor feed stream is heated up to its operating temperature using purely energy provided by hot stream 2 (burner's exhaust gas). The heat recovery below the pinch is treated similarly to the previous situation at a BWR of 0.4. Different split ratio in the hot stream is used to conform with the heat demands from cold stream 1 and 2.

\subsection{Optimized Flow Process}

Both of the designs presented in Figure 5(b) and Figure 5(d) are tested in accordance to their operating conditions. Figure 6 presents the result of the optimization with respect to the thermal efficiency of the system that operates with 8 $\mathrm{wt} \%$ feed at a 0.4 and a $0.6 \mathrm{BWR}$, which are referred to as Case (1) and Case (2) respectively. Figure 6 also shows the result for the system that operates with 12 wt\% at a 0.4 and a 0.6 BWR, which are referred to as Case (3) and Case (4) from further on. 


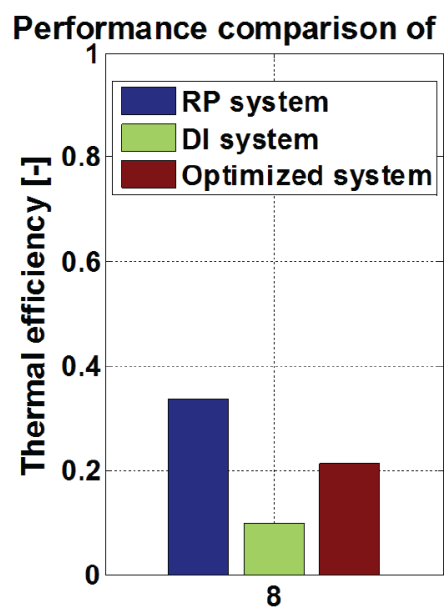

Dry matter content [wt-\%]

(Case 1)

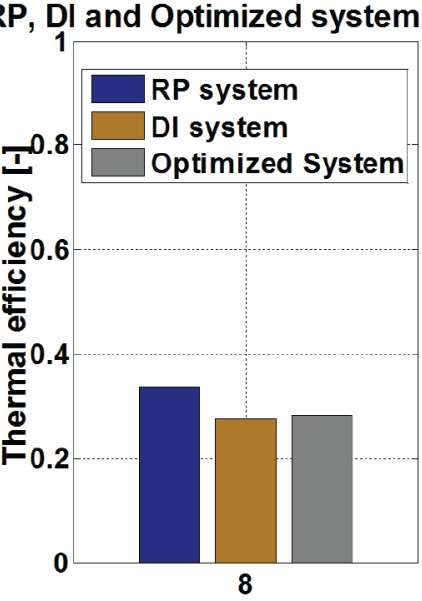

Dry matter content [wt-\%]

(Case 2)

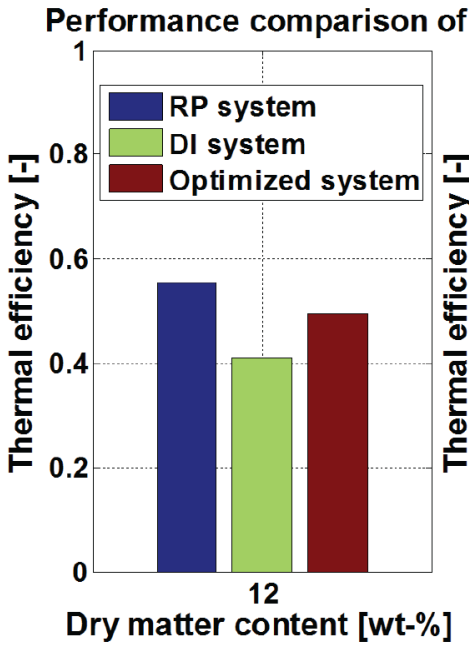

(Case 3)

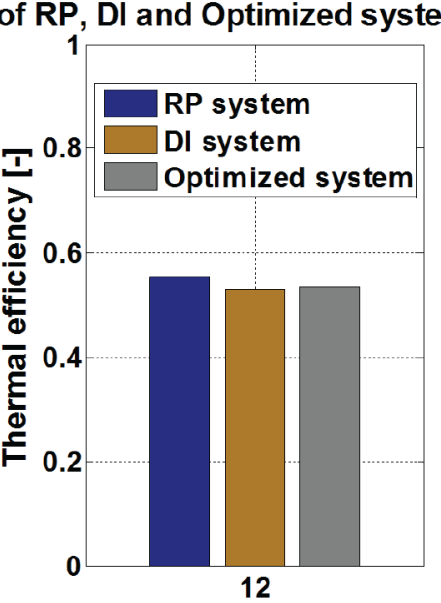

Dry matter content [wt-\%]

(Case 4)

Figure 6. (Case 1-4) Thermal efficiency comparison for system using sewage sludge at $575^{\circ} \mathrm{C}$ and $25 \mathrm{MPa}$; (Case 1) With $8 \mathrm{wt} \% \mathrm{DMC}$ and 0.4 BWR; (Case 2) With 8 wt\% DMC and 0.6 BWR; (Case 3) With 12 wt\% DMC and 0.4 BWR; (Case 4) With $12 \mathrm{wt} \%$ DMC and 0.6 BWR.

It can be seen that in Case (1), the DI system suffers an efficiency loss of $21 \%$ points in comparison to the RP. This efficiency reduction can be decreased to $12 \%$ points with a higher DMC as can be seen in Case (3). After the pinch analysis is applied, the efficiency decrease changes to $12 \%$ and $5 \%$ points for Case (1) and Case (3), respectively.

The reduction in efficiency is not significant when the system operates with 0.6 BWR. The DI system in Case (2) experiences an efficiency reduction of $6 \%$ points in comparison to the RP. After it is optimized, the difference in efficiency is reduced to $4 \%$ points. The effect of pinch optimization is even less pronounced at higher DMC. This slight effect of the pinch optimization can be explained due to the fact that the efficiency reduction of the DI in comparison to 
the RP is not that large at all. Therefore, pinch optimization could not play a big role in this condition.

However, as mentioned in subsection 2.4.2., it should be noted that the maximum DMC a system can handle because of the pumpability is around $20 \mathrm{wt} \%$. It means that the amount of biomass in the injected-feed stream should be at most $20 \mathrm{wt} \%$. The $20 \mathrm{wt} \%$ pumped biomass in the injected-feed stream corresponds to Case (3) (a wt\% DMC with a 0.4 BRW) or Case (2) (an 8 wt\% DMC with a $0.6 \mathrm{RBW})$. This means that the optimized system that operates at a 0.4 BWR has a $50 \%$ efficiency and the system that operates at a 0.6 BWR can only achieve $28 \%$ efficiency. This value can be found in Case (2) and Case (3) in Figure 6. Taking this into consideration it is suggested to operate in accordance to the optimized system that uses a 0.4 BWR.

It should also be noted that Figure 5(b) and Figure 5(d) suggest that the product gas temperature is still higher than $250^{\circ} \mathrm{C}$. There are a lot of potential applications for this residual heat, such as process heating for paper industry, district heating or for heat supply of an organic Rankine cycle system. The influence of combining any of these options with the SCWG technology to improve the utilization factor for the process will be dealt in future studies.

\section{Conclusions}

Implementing a direct injection system at reactor conditions of $575^{\circ} \mathrm{C}$ and 25 $\mathrm{MPa}, \mathrm{a} 0.4$ bypass water ratio and an equal total dry matter content decreases the efficiency by approximately $8 \%-23 \%$ points, in comparison to the reference system with only premixed biomass. Direct injection system has to operate at a temperature above $570^{\circ} \mathrm{C}$ to minimize coke formation. In order to avoid unnecessary loss of thermal efficiency and heat exchanger effectiveness, the upper limit of the operating temperature should be $600^{\circ} \mathrm{C}$. The ratio of bypass water to feed mixture should be around $0.4-0.5$ in order to have the most efficient system. The inclination of the upward curve is going flatter with further increase of this ratio.

An increase of the thermal efficiency is obtained after the implementation of the pinch analysis result at $575^{\circ} \mathrm{C}$ and $25 \mathrm{MPa}$. In case the system operates at a 0.4 bypass ratio, an improvement of thermal efficiency from $9.8 \%$ to $22 \%$ for a total of $8 \mathrm{wt} \%$ and from $41 \%$ to $50 \%$ for a total of $12 \mathrm{wt} \%$ dry matter content, is possible. When the system operates at a 0.6 bypass ratio, a very slight improvement in thermal efficiency is obtained. Literature states that currently pump can pump a feed stream with a maximum of $20 \mathrm{wt} \%$ dry matter content. If the direct injection system operates at 0.4 bypass ratio, then $12 \mathrm{wt} \%$ dry matter content in the total feed stream is divided and a stream with $20 \mathrm{wt} \%$ dry matter content will be pumped. The $12 \mathrm{wt} \%$ value is translated into $8 \mathrm{wt} \%$ dry matter content in the total feed stream if the direct injection system operates at a 0.6 bypass ratio. Taking this into consideration, it is more beneficial to operate with a bypass water ratio of 0.4 with a total feed concentration of $8-12 \mathrm{wt} \%$. 


\section{Acknowledgements}

This work is supported by the AgentschapNL (RVO) TKI-Scarlet plus program. For this, the authors would like to express their gratitude. The authors would also like to convey their thanks to all project partners involved within this framework, especially to Jo Penninger (SPARQLE International BV) who passed away before this publication was finished. This research also draws inspiration from the work of one our students, Vasilis Trakas, for which the authors are very grateful.

\section{References}

[1] Parikka, M. (2004) Global Biomass Fuel Resources. Biomass Bioenergy, 27, 613-620. https://doi.org/10.1016/j.biombioe.2003.07.005

[2] D’Jesús, P., Boukis, N., Kraushaar-Czarnetzki, B. and Dinjus, E. (2006) Gasification of Corn and Clover Grass in Supercritical Water. Fuel, 85, 1032-1038. https://doi.org/10.1016/j.fuel.2005.10.022

[3] Bröll, D., Kaul, C., Krämer, A., Krammer, P., Richter, T., Jung, M., Vogel, H. and Zehner, P. (1999) Chemistry in Supercritical Water. Angewandte Chemie International Edition, 38, 2998-3014.

https://doi.org/10.1002/(SICI)1521-3773(19991018)38:20<2998::AID-ANIE2998>3. $\underline{0 . \mathrm{CO} ; 2-\mathrm{L}}$

[4] Kruse, A. (2009) Hydrothermal Biomass Gasification. The Journal of Supercritical Fluids, 47, 391-399. https://doi.org/10.1016/j.supflu.2008.10.009

[5] Susanti, R.F., Dianningrum, L.W., Yum, T., Kim, Y., Lee, B.G. and Kim, J. (2012) High-Yield Hydrogen Production from Glucose by Supercritical Water Gasification without Added Catalyst. International Journal of Hydrogen Energy, 37, 11677-11690. https://doi.org/10.1016/j.ijhydene.2012.05.087

[6] Basu, P. and Mettanant, V. (2009) Biomass Gasification in Supercritical Water-A Review. International Journal of Chemical Reactor Engineering, 7.

[7] Waldner, M.H. (2007) Catalytic Hydrothermal Gasification of Biomass for the Production of Synthetic Natural Gas. Eidgenössische Technische Hochschule/Paul Scherrer Institute, Zürich.

[8] Kruse, A. (2008) Supercritical Water Gasification. Biofuels, Bioproducts and Biorefining, 2, 415-437. https://doi.org/10.1002/bbb.93

[9] Matsumura, Y., Minowa, T., Potic, B., Kersten, S.R.A., Prins, W., van Swaaij, W.P.M., van de Beld, B., Elliott, D.C., Neuenschwander, G.G., Kruse, A. and Jerry Antal Jr, M. (2005) Biomass Gasification in Near- and Super-Critical Water: Status and Prospects. Biomass Bioenergy, 29, 269-292. https://doi.org/10.1016/j.biombioe.2005.04.006

[10] Guo, L., Jin, H. and Lu, Y. (2015) Supercritical Water Gasification Research and Development in China. The Journal of Supercritical Fluids, 96, 144-150. https://doi.org/10.1016/j.supflu.2014.09.023

[11] Amrullah, A. and Matsumura, Y. (2018) Supercritical Water Gasification of Sewage Sludge in Continuous Reactor. Bioresource Technology, 249, 276-283. https://doi.org/10.1016/j.biortech.2017.10.002

[12] Rodriguez Correa, C. and Kruse, A. (2017) Supercritical Water Gasification of Biomass for Hydrogen Production-Review. The Journal of Supercritical Fluids. https://doi.org/10.1016/j.supflu.2017.09.019 
[13] Yakaboylu, O., Harinck, J., Smit, K. and de Jong, W. (2015) Supercritical Water Gasification of Biomass: A Literature and Technology Overview. Energies, 8, 859. https://doi.org/10.3390/en8020859

[14] Knežević, D., van Swaaij, W.P.M. and Kersten, S.R.A. (2009) Hydrothermal Conversion of Biomass: I, Glucose Conversion in Hot Compressed Water. Industrial \& Engineering Chemistry Research, 48, 4731-4743. https://doi.org/10.1021/ie801387v

[15] Karayıldırım, T., Sınağ, A. and Kruse, A. (2008) Char and Coke Formation as Unwanted Side Reaction of the Hydrothermal Biomass Gasification. Chemical Engineering \& Technology, 31, 1561-1568. https://doi.org/10.1002/ceat.200800278

[16] Chuntanapum, A. and Matsumura, Y. (2009) Formation of Tarry Material from 5-HMF in Subcritical and Supercritical Water. Industrial \& Engineering Chemistry Research, 48, 9837-9846. https://doi.org/10.1021/ie900423g

[17] Chuntanapum, A. and Matsumura, Y. (2010) Char Formation Mechanism in Supercritical Water Gasification Process: A Study of Model Compounds. Industrial \& Engineering Chemistry Research, 49, 4055-4062. https://doi.org/10.1021/ie901346h

[18] Yoshida, T. and Matsumura, Y. (2009) Reactor Development for Supercritical Water Gasification of $4.9 \mathrm{wt} \%$ Glucose Solution at $673 \mathrm{k}$ by Using Computational Fluid Dynamics. Industrial \& Engineering Chemistry Research, 48, 8381-8386. https://doi.org/10.1021/ie9002188

[19] Zöhrer, H., Mayr, F. and Vogel, F. (2013) Stability and Performance of Ruthenium Catalysts Based on Refractory Oxide Supports in Supercritical Water Conditions. Energy Fuels, 27, 4739-4747. https://doi.org/10.1021/ef400707f

[20] Yukananto, R., Louwes, A.C., Brem, G. and Brammer, E.A. (2016) Direct and Standard Injection of Sewage Sludge in a Supercritical Water Gasification System-Optimization of the Energy Efficiency using Pinch Analysis. 24th European Biomass Conference and Exhibition, Amsterdam.

[21] Boukis, N., Galla, U., D’Jesus, P., Muller, H. and Dinjus, E. (2005) Gasification of Wet Biomass in Supercritical Water. Results of Pilot Plant Experiments. 14th European Biomass Conference and Exhibition, Paris.

[22] Boukis, N., Galla, U., Muller, H. and Dinjus, E. (2007) Biomass Gasification in Supercritical Water, Experimental Progress Achieved with the Verena Pilot Plant. 15th European Biomass Conference and Exhibition, Berlin.

[23] Withag, A.M., Smeets, J.R., Bramer, E.A. and Brem, G. (2012) System Model for Gasification of Biomass Model Compounds in Supercritical Water-A Thermodynamic Analysis. The Journal of Supercritical Fluids, 61, 157-166.

https://doi.org/10.1016/j.supflu.2011.10.012

[24] Marias, F., Letellier, S., Cezac, P. and Serin, J.P. (2011) Energetic Analysis of Gasification of Aqueous Biomass in Supercritical Water. Biomass Bioenergy, 35, 59-73.

https://doi.org/10.1016/j.biombioe.2010.08.030

[25] Mateos-Espejel, E., Savulescu, L., Maréchal, F. and Paris, J. (2011) Unified Methodology for Thermal Energy Efficiency Improvement: Application to Kraft Process. Chemical Engineering Science, 66, 135-151. https://doi.org/10.1016/j.ces.2010.09.032

[26] Bendig, M., Maréchal, F. and Favrat, D. (2013) Defining "Waste Heat" for Industrial Processes. Applied Thermal Engineering, 61, 134-142. https://doi.org/10.1016/j.applthermaleng.2013.03.020

[27] Puig-Arnavat, M., Bruno, J.C. and Coronas, A. (2010) Review and Analysis of Biomass Gasification Models. Renewable \& Sustainable Energy Reviews, 14, 2841-2851. https://doi.org/10.1016/j.rser.2010.07.030 
[28] Ahmed, T.Y., Ahmad, M.M., Yusup, S., Inayat, A. and Khan, Z. (2012) Mathematical and Computational Approaches for Design of Biomass Gasification for Hydrogen Production: A Review. Renewable \& Sustainable Energy Reviews, 16, 2304-2315. https://doi.org/10.1016/j.rser.2012.01.035

[29] Voll, F.A.P., Rossi, C.C.R.S., Silva, C., Guirardello, R., Souza, R.O.M.A., Cabral, V.F. and Cardozo-Filho, L. (2009) Thermodynamic Analysis of Supercritical Water Gasification of Methanol, Ethanol, Glycerol, Glucose and Cellulose. International Journal of Hydrogen Energy, 34, 9737-9744.

https://doi.org/10.1016/j.ijhydene.2009.10.017

[30] Yan, Q., Guo, L. and Lu, Y. (2006) Thermodynamic Analysis of Hydrogen Production from Biomass Gasification in Supercritical Water. Energy Conversion and Management, 47, 1515-1528. https://doi.org/10.1016/j.enconman.2005.08.004

[31] Lutz, A.E., Bradshaw, R.W., Keller, J.O. and Witmer, D.E. (2003) Thermodynamic Analysis of Hydrogen Production by Steam Reforming. International Journal of Hydrogen Energy, 28, 159-167. https://doi.org/10.1016/S0360-3199(02)00053-8

[32] Valderrama, J.O. (2003) The State of the Cubic Equations of State. Industrial \& Engineering Chemistry Research, 42, 1603-1618. https://doi.org/10.1021/ie020447b

[33] Stolten, D. and Emonts, B. (2016) Hydrogen Science and Engineering: Materials, Processes, Systems and Technology. John Wiley \& Sons.

https://doi.org/10.1002/9783527674268

[34] ECN (2016) Sewage Sludge Composition. https://www.ecn.nl/phyllis2/Biomass/View/1179

[35] Louw, J., Schwarz, C.E., Knoetze, J.H. and Burger, A.J. (2014) Thermodynamic Modelling of Supercritical Water Gasification: Investigating the Effect of Biomass Composition to Aid in the Selection of Appropriate Feedstock Material. Bioresource Technology, 174, 11-23. https://doi.org/10.1016/j.biortech.2014.09.129 